\title{
Organizational Politics and Organizational Citizenship Behavior: Interaction and Analysis
}

\author{
Ahmad Albloush $^{1 *}$, Hasan Al-Zu'bi ${ }^{1}$, Alhareth Abuhussien ${ }^{1}$, Imad Almuala ${ }^{1}$, Ghassan Al-Utaibi ${ }^{2}$, Sadi Taha $^{3}$, \\ Azlinzuraini Ahmad ${ }^{4}$ \\ ${ }^{1}$ Faculty of Business, Amman Arab University, Amman 11934, Jordan \\ ${ }^{2}$ Rochester Institute of Technology, Dubai 341055, UAE \\ ${ }^{3}$ School of Business Administration, Aldar University College, Dubai 35529, UAE \\ ${ }^{4}$ Economics and Social Development, Faculty of Business, University Malaysia Terengganu, Terengganu 21030, Malaysia
}

Corresponding Author Email: bloush@aau.edu.jo

https://doi.org/10.18280/ijsdp.160520

Received: 20 April 2021

Accepted: 4 June 2021

\section{Keywords:}

$O C B-I, O C B-O, O P$, public sector

\begin{abstract}
Perceptions of organizational politics are an essential aspect of organizational life for its members because they impact different practices, which eventually affect employee efficiency. This article is explored the relationship between Organizational Politics (OP) and Organizational Citizenship Behavior (organizational citizenship behavior for organization (OCB-O) and organizational citizenship behavior for individuals (OCB-I). Survey data is gathered from 200 employees work in Jordanian public sector. Partial least square (PLS-SEM) is employed to test the research hypotheses. Outcomes uncovered that OP has a negative relationship with OCB-O and OCB-I. Accordingly, the current study recommends that governments abolish or restrict OP activities in their organizations as much as possible. Besides, the findings show that OP activities harmed public-sector employee behavior. The study's limitations and recommendations for future studies are also considered.
\end{abstract}

\section{INTRODUCTION}

Organizational citizenship behavior (OCB) is one of the contemporary concepts that has strengthened interest in it during the last two decades, because of this concept of a prominent impact on the level of employee performance. The achievement of organizations today depends on the enthusiasm of their employees to achieve performance levels that exceed the set goals and objectives [1]. According to AlMahasneh [2], OCB refers to anything good that employees do. Furthermore, the study found that organizations should foster OCB in the workplace by motivating employees and creating a workplace atmosphere that encourages OCB. Borman et al. [3] demonstrated that many organizations have been focused on OCB, while Jahangir et al. [4] reported that employees of organizations must be prepared to do more than the minimum structured and specific aspects of their job functions.

The public sector in Jordan, which suffers from the absence of clear goals and central of in decision-making and the consequent failure to meet the needs of its employees, is in dire need to instill OCB among its employees. Because of its positive effects on the performance and reputation of public sector organizations, including improving performance, raising the morale of workers, and increase their job satisfaction, and reflected in the manner of dealing with citizens [1]. Albloush et al. [5] pointed out that OCB is very important in Jordanian municipalities, which are part of public sector to enhance and increase job performance, and the municipal should instill OCB among employees, to increase their performance and provide the best services to citizens.

Distinguishing between OCBs directed at individuals $(\mathrm{OCBI})$ and those directed at organizations (OCBO) has been proposed by McNeely and Meglino [6]. OCBO is a direct result of how workers perceive their job characteristics. In comparison, OCBI seems to have only indirect consequences for preserving equilibrium in the organization-employee transaction [7].

Individuals' behavior is modified by the expectation principle based on their estimation of expected outcomes [8]. OP also interferes with organizational processes such as promotions and incentives, and it has often harmed organizational productivity and employee results $[9,10]$. The nature of OP in the public sector has also received publicity, with some suggesting that this sector has higher levels of politics than the private sector [11], as well as it has a negative effect on public trust in government [12]. Organizational politics, on the other hand, is regarded as a disruptive phenomenon that can undermine citizenship activity.

Based on above survey, several studies focus on the impact or the relationship between OP, Job performance and job satisfaction. As well as, prior studies were conduct in Some Asian countries, USA, and some Europe countries. Few studies, and none recently studies conduct in Arab countries, link between OP and OCB. Therefore, the current article is aims to explore the relationship between OP, OCBO and OCBI among public sector employees in Jordan.

\section{BACKGROUND}

\subsection{Organizational Citizenship Behavior (OCB)}

OCB in the institution is receiving much attention from scholars [13]. The definition of OCB dates back to Katz's [14] 
study, which claimed that companies could improve their efficiency by relying on voluntary employee habits that were not mandated by top management. Correspondingly, Bateman and Organ [15] saw OCB as a conduct above and above a position that cannot be placed on workers and stems from feelings of reciprocity. Hence, OCB defines discretionary conduct as "individual behavior that is not directly or indirectly acknowledged by the structured rewards system and that, in aggregate, facilitates the successful functioning of the organization" [16]. While the OCB does not explicitly pay workers and does not extend formal employee work definitions, it may have a substantial influence on employees [17].

Organ [16] introduced OCB and reconsidered the old-style concept of job performance. Organ observed that, in addition to the quantitative aspects of the job, job success contained certain qualitative aspects that he referred to as the OCB, which added to the social and psychological sense of work. OCB is critical to both the company and the client. The significance of this activity stems from the fact that it contributes to the overall success of the company by establishing a foundation of mutual relationships between employees from various departments. Often, by allocating more time for effective preparation, scheduling of tasks, and problem solving, this action increases managers' and colleagues' ability to do their jobs reduces the need to commit limited resources to maintenance tasks $[17,18]$.

Several dimensions of OCB have been established in previous studies. Borman and Motowidlo [18] define OCB as "the extra effort and enthusiasm that employees put forth in work tasks; voluntary participation in tasks that fall beyond the assigned task set". Furthermore, Williams and Anderson [19] differentiate between citizenship activities directed toward the organization (OCBO) and toward individuals (OCBI).

The importance of impact and interpretation can differ depending on whether OCBI or OCBO is being considered. If OCB is a deliberate effort to establish a balance in social interaction between workers and the organization, it is fair to conclude that this action is specifically aimed at helping the organization [7]. As a result, OCBO is probable to be a direct feature of how workers perceive their job characteristics. OCBI, on the other hand, tends to have indirect consequences, at best, of preserving equilibrium in the organizationemployee ties [7]. The OCB concept has more recently been extended to include not only the categories of altruism and generalized conformity and altruism (help action directed at particular people) but also courtesy and sports and civil rights [7].

OCBO has a stronger relationship with employee values than OCBI. Employee work perception, such as incentives and acknowledgment, was correlated with OCBO but not with OCBI, according to McNeely and Meglino [6]. Furthermore, according to Skarlicki and Latham [20], fairness perceptions were more closely linked to OCBO than to OCBI.

\subsection{Organizational politics (OP)}

$\mathrm{OP}$ is a dynamic phenomenon, and its impact on organizational outcomes such as success, job satisfaction, and engagement are difficult to quantify [10]. Tushman [21] defines OP as a behavior for controlling decision making; however, many others characterize OP in organizations as a self-serving behavior [22]. OP is described similarly by Ferris et al. [22] as "a social control mechanism in which action is strategically engineered to maximize short-term or long-term self interest. According to Vigoda [10], OP may be more harmful to public administration than to private organizations. The significance of OP is based on its possible effects and effect on job outcomes. Employee impressions of organizational politics (POP) are one field that researchers have empirically studied, whereas political attitudes are another. Ferris and Kacmar [23] proposed POP as a good measure of the general political climate in organizations and a significant component of individuals' perceptions of their work environment. Individuals respond to situations and engage in actions based on their expectations.

According to Cropanzano et al. [24], many people view organizational politics as a challenge to their well-being, resulting in a number of negative affective reactions such as increased work anxiety and decreased job satisfaction. Organizational factors, work environment factors, and personal factors all influence POP, which in turn influences individual and organizational results such as organizational withdrawal, job anxiety, job commitment, and job satisfaction. Organizational politics is likely to be viewed as a challenge by workers who experience high levels of organizational politics and believe they have little influence over these organizational processes [23].

Organizational politics, on the other hand, would be seen as an incentive to encourage workers' self-interests if they believe they have power over organizational processes. POP have been extensively studied and have been linked to antecedents (personal factors, situational factors) and significant outcomes (psychological outcomes, attitudinal outcomes, and behavioral outcomes). Organizational politics attitudes have been linked to negative work outcomes such as decreased job commitment, decreased job satisfaction, increased intent to turnover, and anxiety [23]. In addition, it decreased satisfaction with supervisors.

\subsection{Link between OP and OCB}

Employees experience high levels of anxiety when they are persuaded that corporate decision-making is marked by strong self-service habits, as they believe that these behaviors may jeopardize their aptitude to fulfill their job obligations [25]. This should lessen the risk of them engaging in tasks that are not part of their official job description [26]. OP can weaken incentives to participate in OCB in addition to restricting their desire to engage in such behaviors.

Employees who assume that self-service situations control corporate decision-making are more likely to be disappointed or even angry, damaging their work satisfaction and career status in general [27]. Furthermore, social exchange theory submits that when workers perceive the company to be supportive and favorable, they attempt to reciprocate with positive responses. Similarly, when workers consider the organization to be unfavorable to them, they respond by rising unfavorable responses or decreasing positive replies to the organization.

It has frequently been found that OP impedes organizational growth by rising the probability of negative work attitudes and behaviors [28]. Furthermore, there is a close association between OP and OCB, with an increase in OP resulting in a decrease in OCB [12]. Atta and Khan [28] used a survey of 494 students from various public universities in Pakistan to find that OP has a negative effect on OCB. In a similar vein, data from a Mexican manufacturing company show that $\mathrm{OP}$ 
lowers OCB [29].

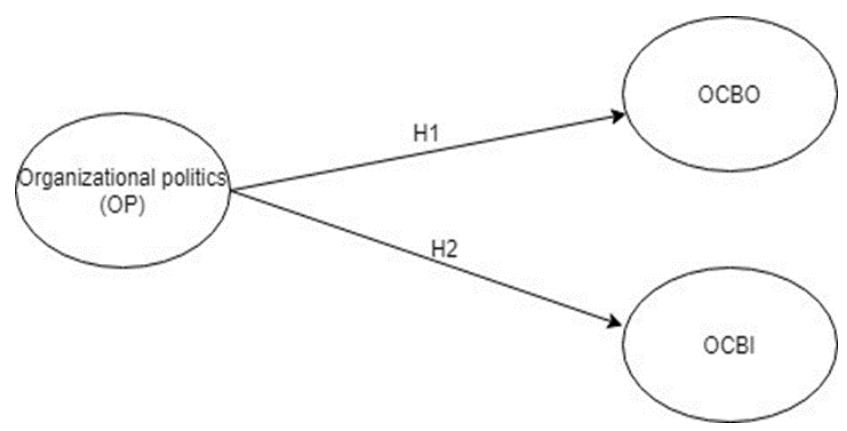

Figure 1. Cavity geometry

Khan et al. [30] used social exchange theory to describe how the OP influences the OCB. The analysis relies on a survey of 392 supervisor-subordinate dyads from Southern Chinese tour companies.

The results show that, OP negatively predicted OCB via moral efficacy. Therefore, we develop our hypothesis as follows:

Hypothesis 1: There is a negative relationship between $O P$ and $O C B O$

Hypothesis 2: There is a negative relationship between OP and $O C B I$
Accordingly, Figure 1 shows a research framework of the current study.

\section{DATA AND METHODOLOGY}

The public sector in this study includes (Ministry of health, Ministry of industry and commerce, Ministry of local administration, Greater Amman municipality, Civil Status and passport Department, and Income and Sales Tax Department). The researcher design E-survey (google form) and distribute hard copy to collect data and agree with human resources department in each mention organization to send the link to the employees and distribute the hard copy. Subsequently, 200 respond received.

The respondents' profiles are depicted in Table 1. It appears that majority of respondents are male $(90.5 \%)$ and most of them are between 29 to 39 years old (44.4\%), qualified with Bachelor's degree $(33.3 \%)$, and with work experience of at least 5 to 15 years $(46.4 \%)$.

The instruments used in the current study have been adopted from prior literature and it used a 5-point Likert scale (i.e. varying from (1) represented strongly disagree to (5) represented strongly agree). Seven items to determine OCB-O and seven items to determine OCB-I adapted from Lee and Allen [7], thirteen items adapted from Kacmar and Carlson's [31] measured organizational politics.

Table 1. Profile of respondents $(\mathrm{N}=200)$

\begin{tabular}{cccc}
\hline Variables & Category & Percentage & Percentage \\
\hline \multirow{2}{*}{ Gender } & Male & 181 & 90.5 \\
& Female & 19 & 9.5 \\
\hline \multirow{2}{*}{ Age } & $19-28$ & 6 & 3.2 \\
& $29-39$ & 89 & 44.4 \\
& $40-50$ & 75 & 37.3 \\
Working Experience & $>50$ & 30 & 15.1 \\
& $5<$ & 35 & 17.6 \\
& $5-15$ & 93 & 46.4 \\
& $16-26$ & 53 & 26.4 \\
& $>27$ & 19 & 9.6 \\
\hline \multirow{2}{*}{ Education Level } & High School or Less & 49 & 24.6 \\
& Diploma & 22 & 11.1 \\
& Bachelor's degree & 67 & 33.3 \\
& Master degree & 33 & 17.7 \\
& Ph.D. & 29 & 14.3 \\
\hline
\end{tabular}

\section{RESULTS AND DISCUSSION}

\subsection{Results of measurement model}

The current article employed structural equation modelling (SEM) to evaluate the conceptual model and to test the hypotheses. The measurement model was test through the convergent validity and discriminant validity. To evaluate the convergent validity, results of the factor loadings, composite reliability (CR) and average variance extracted (AVE) were inspected [32]. Items having a loading of more than 0.50 are acceptable for analysis, AVE of at least a value of 0.5 , and CR having a value exceeding 0.7 , are to be retained. Table 2 displays that all the latent constructs have provided convergent validity since the factor loadings are between 0.563 to 0.835 , the CR values are above 0.80 and the AVE values are more than 0.50 .

The measurement model was tested using discriminant validity. To build discriminant validity, the criterion and cross-loading scores of Fornell and Larcker [33] are employed. Table 3 demonstrates that for all latent variables the square root of AVE was larger than interconstruction correlations supporting validity.

\subsection{Structural model results}

The importance of path coefficients was investigated using a PLS algorithm and standard bootstrapping procedures in this analysis [34]. Table 4 displays the path coefficient values and bootstrapping outcomes.

Figure 2 depicts the research model proposed in this report. As exhibited, the R2 values for OCB-O and OCB-I were 0.189 and 0.116 , respectively, implying that $\mathrm{OP}$ can explain $18.9 \%$ of the variance in OCB-O and $11.6 \%$ of the variance in OCB-I. 
Table 2. Virous items of the measurement model

\begin{tabular}{|c|c|c|c|c|}
\hline Constructs & Items & Items loading & $\mathbf{C R}$ & AVE \\
\hline Organizational politics (OP) & $\begin{array}{c}\text { OP1 } \\
\text { OP2 } \\
\text { OP3 } \\
\text { OP4 } \\
\text { OP5 } \\
\text { OP6 } \\
\text { OP7 } \\
\text { OP8 } \\
\text { OP9 } \\
\text { OP10 } \\
\text { OP11 } \\
\text { OP12 } \\
\text { OP13 }\end{array}$ & $\begin{array}{l}0.80 \\
0.81 \\
0.76 \\
0.80 \\
0.80 \\
0.83 \\
0.81 \\
0.71 \\
0.73 \\
0.76 \\
0.74 \\
0.74 \\
0.78\end{array}$ & 0.95 & 0.60 \\
\hline OCB-O & $\begin{array}{l}\text { OCBO-1 } \\
\text { OCBO-2 } \\
\text { OCBO-3 } \\
\text { OCBO-4 } \\
\text { OCBO-5 } \\
\text { OCBO-6 } \\
\text { OCBO-7 }\end{array}$ & $\begin{array}{l}0.79 \\
0.80 \\
0.82 \\
0.65 \\
0.69 \\
0.71 \\
0.64 \\
\end{array}$ & 0.89 & 0.54 \\
\hline OCB-I & $\begin{array}{l}\text { OCBI-1 } \\
\text { OCBI-2 } \\
\text { OCBI-3 } \\
\text { OCBI-4 } \\
\text { OCBI-5 } \\
\text { OCBI-6 } \\
\text { OCBI-7 } \\
\end{array}$ & $\begin{array}{l}0.69 \\
0.80 \\
0.68 \\
0.80 \\
0.83 \\
0.58 \\
0.56 \\
\end{array}$ & 0.87 & 0.51 \\
\hline
\end{tabular}

Table 3. Discriminant validity analysis

\begin{tabular}{cccc}
\cline { 2 - 4 } & OCB-I & OCB-O & OP \\
\cline { 2 - 4 } OCB-I & 0.715 & & \\
OCB-O & 0.534 & 0.735 & \\
OP & -0.341 & -0.434 & 0.780 \\
\hline
\end{tabular}

OP had a negative relationship with OCB-O and OCB-I, as shown in Table $4(\beta=-0.434 ; \mathrm{t}=5.522 ; \mathrm{p}<0.001 ; \beta=$ $0.341 ; \mathrm{t}=4.437 ; \mathrm{p}<0.001)$. As a result, $\mathrm{H} 1$ and $\mathrm{H} 2$ were accepted. Accordingly, employees working in an OP-infested environment who prefer to protect their jobs may respond with apathy to their work to this environment. This matter has a negative impact on their behavior (OCB-O and OCB-I). According to the current report, $\mathrm{OP}$ triggered negative emotions and cognitions that influenced employee behavior.

Employees in the public sector who served in an atmosphere where OP was widespread experienced feelings of deprivation and inequity, which led to poor conduct. Employees were extremely demotivated and disliked their jobs as they felt that people relied on political actions to realize their own goals, and they did not exhibit extra role activity or OCB. This finding is consistent with the previous result $[12,25,29]$.

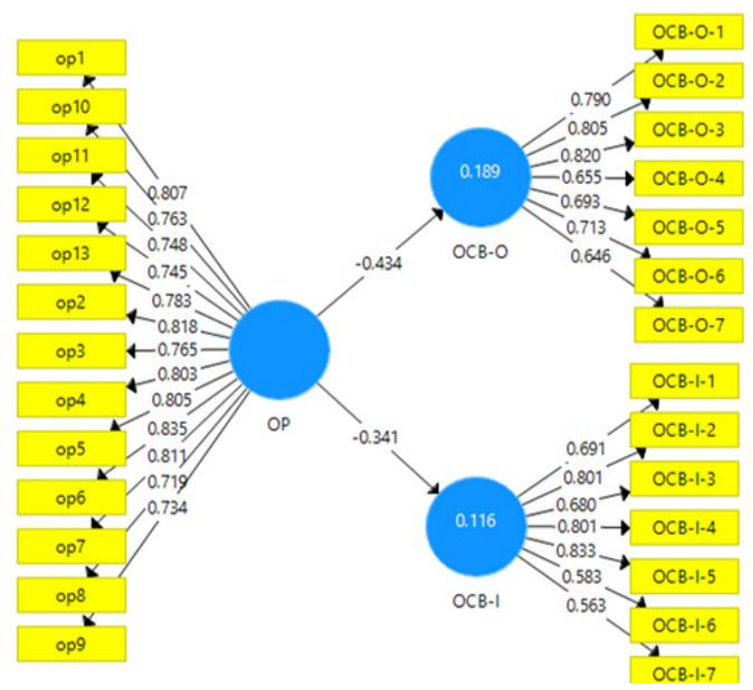

Figure 2. Cavity geometry

Table 4. Testing of hypotheses

\begin{tabular}{cccccc}
\hline Path & Hypothesis & Path Coefficients & t-value & p-value & Decision \\
\hline $\mathrm{OP} \rightarrow \mathrm{OCB}-\mathrm{O}$ & $\mathrm{H} 1$ & -0.434 & 5.522 & 0.000 & Supported \\
\hline $\mathrm{OP} \rightarrow$ OCB-I & $\mathrm{H} 2$ & -0.341 & 4.437 & 0.000 & Supported \\
\hline
\end{tabular}

\section{CONCLUSION}

The relationship between OP, OCB-O, and OCB-I was investigated in the current study. There was a skewed partnership between OP and OCB. As a result, high levels of
OP were decreased, as was employee behavior. As a result, executives must ensure that structured procedures and regulations are acceptable for employees. Furthermore, this study found that OP activities harmed public-sector employee behavior. 
This study's results have practical consequences as well. It is recommended that Jordanian public sector managers or policy makers make an effort to minimize or eradicate the OP practice in their respective organizations. This is one of only a few studies conducted in Arabic-speaking countries and in the public sector. This is can considered as an essential because the majority of OP and OCB (OCB-O and OCB-I) studies have been performed in non-Arabic countries such as Pakistan, Mexico, and China. This is the first investigation.

\section{LIMITATION AND FUTURE RESEARCH}

The small sample size for this study, which depends on the employees of some public sector institutions in one country (Jordan), may be a weakness of its application. As a consequence, the generalizability of the findings may be limited due to the small sample size. Large sample sizes, on the other hand, may be used in future studies.

There are also drawbacks in that people's views of politics and citizenship attitudes are framed differently. Politics refers to a person's actions in theoretical debates, while corporate citizenship refers to the behavior of the whole organization. As a result, future research might resolve this issue by allowing respondents to specifically consider the organizational and OCB policies of various social organizations.

On the other hand, workers may be especially vulnerable to the stresses associated with political behavior. The hegemony of collectivism that characterizes Arab culture can have an effect on research findings. As a result, cross-country research should compare the relative significance of organizational policies in reinforcing the propensity to follow behaviors requiring informal demand in various cultural contexts.

As mentioned early, this study incorporated employees from few governmental organizations. In this way, the relationship between OP and OCB may be conceptualized as indirect, indicating a possible presence of some mediators and moderator, therefore this study recommends to use a mediator or moderator variable between OP and OCB, such as fairness or rewards.

\section{REFERENCES}

[1] Al-Bashabsheh, S., Al-Harahsheh, M. (2011). The impact of motivation dimensions on organizational citizenship behavior: A field study from the perspective of workers in the municipalities of the southern governorates of Jordan. Jordan Journal in Business Administration, 7(4): 647-680.

[2] Al-Mahasneh, M.A. (2015). The impact of organizational citizenship behavior on job performance at Greater Amman municipality. European Journal of Business and Management, 7(36): 108-118.

[3] Borman, W.C., Penner, L.A., Allen, T.D., Motowidlo, S.J. (2001). Personality predictors of citizenship performance. International Journal of Selection and Assessment, 9(1-2):

52-69. https://doi.org/10.1111/1468-2389.00163

[4] Jahangir, N., Akbar, M.M., Haq, M. (2004). Organizational citizenship behavior: Its nature and antecedents. BRAC University Journal, 1(2): 75-85.

[5] Albloush, A., Taha, S., Nassoura, A., Vij, A., Bohra, O.P., Masouad, N., Hussien, A.A. (2020). Impact of organizational citizenship behavior on job performance in Jordan: The mediating role of perceived training opportunities. International Journal of Psychosocial Rehabilitation, 24(05). https://doi.org/10.37200/IJPR/V24I5/PR2020264

[6] McNeely, B.L., Meglino, B.M. (1994). The role of dispositional and situational antecedents in prosocial organizational behavior: An examination of the intended beneficiaries of prosocial behavior. Journal of Applied Psychology, 79(6): 836-844. https://doi.org/10.1037/0021-9010.79.6.836

[7] Lee, K., Allen, N.J. (2002). Organizational citizenship behavior and workplace deviance: The role of affect and cognitions. Journal of Applied Psychology, 87(1): 131142. https://doi.org/10.1037/0021-9010.87.1.131

[8] Chen, Y.Y., Fang, W. (2008). The moderating effect of impression management on the organizational politicsperformance relationship. Journal of Business Ethics, 79(3): 263-277. https://doi.org/10.1007/s10551-0079379-3

[9] Mayes, B.T., Allen, R.W. (1977). Toward a definition of organizational politics. Academy of Management Review, 2(4): 672-678.

[10] Vigoda, E. (2000). Organizational politics, job attitudes, and work outcomes: Exploration and implications for the public sector. Journal of Vocational Behavior, 57(3): 326-347. https://doi.org/10.1006/jvbe.1999.1742

[11] Vigoda-Gadot, E., Kapun, D. (2005). Perceptions of politics and perceived performance in public and private organisations: A test of one model across two sectors. Policy \& Politics, 33(2): 251-276.

[12] Vigoda-Gadot, E. (2007). Leadership style, organizational politics, and employees' performance: An empirical examination of two competing models. Personnel Review.

[13] Eatough, E.M., Chang, C.H., Miloslavic, S.A., Johnson, R.E. (2011). Relationships of role stressors with organizational citizenship behavior: a meta-analysis. Journal of Applied Psychology, 96(3): 619-632.

[14] Katz, D. (1964). The motivational basis of organizational behavior. Behavioral Science, 9(2): 131-146. https://doi.org/10.1002/bs.3830090206

[15] Bateman, T.S., Organ, D.W. (1983). Job satisfaction and the good soldier: The relationship between affect and employee "citizenship". Academy of management Journal, 26(4): 587-595. https://doi.org/10.2307/255908

[16] Organ, D.W. (1988). Organizational Citizenship Behavior: The Good Soldier Syndrome. Lexington Books/DC Heath and Com.

[17] Podsakoff, N.P., Whiting, S.W., Podsakoff, P.M., Blume, B.D. (2009). Individual-and organizational-level consequences of organizational citizenship behaviors: A meta-analysis. Journal of applied Psychology, 94(1): 122.

[18] Borman, W.C., Motowidlo, S.M. (1993). Expanding the criterion domain to include elements of contextual performance. Psychology Faculty Publications.

[19] Williams, L.J., Anderson, S.E. (1991). Job satisfaction and organizational commitment as predictors of organizational citizenship and in-role behaviors. Journal of Management, 17(3): 601-617. https://doi.org/10.1177/014920639101700305

[20] Skarlicki, D.P., Latham, G.P. (1997). Leadership training in organizational justice to increase citizenship behavior within a labor union: A replication. Personnel 
Psychology,

50(3):

$617-633$

https://doi.org/10.1111/j.1744-6570.1997.tb00707.x

[21] Tushman, M.L. (1977). A political approach to organizations: A review and rationale. Academy of Management Review, 2(2): 206-216. https://doi.org/10.5465/amr.1977.4409042

[22] Ferris, G.R., Harris, J.N., Russell, Z.A., Maher, L.P. (2018). Politics in organizations.

[23] Ferris, G.R., Kacmar, K.M. (1992). Perceptions of organizational politics. Journal of Management, 18(1): 93-116. https://doi.org/10.1177/014920639201800107

[24] Cropanzano, R., Howes, J.C., Grandey, A.A., Toth, P. (1997). The relationship of organizational politics and support to work behaviors, attitudes, and stress. Journal of Organizational Behavior, 18(2): 159-180. https://doi.org/10.1002/(SICI)10991379(199703)18:2<159::AID-JOB795>3.0.CO;2-D

[25] Crawford, E.R., LePine, J.A., Rich, B.L. (2010). Linking job demands and resources to employee engagement and burnout: A theoretical extension and meta-analytic test. Journal of Applied Psychology, 95(5): 834-848. https://doi.org/10.1037/a0019364

[26] Chang, C.H., Rosen, C.C., Siemieniec, G.M., Johnson, R.E. (2012). Perceptions of organizational politics and employee citizenship behaviors: Conscientiousness and self-monitoring as moderators. Journal of Business and Psychology, 27(4): 395-406. https://doi.org/10.1007/s10869-012-9257-6

[27] Chang, C.H., Rosen, C.C., Levy, P.E. (2009). The relationship between perceptions of organizational politics and employee attitudes, strain, and behavior: A meta-analytic examination. Academy of Management Journal, 52(4): 779-801. https://doi.org/10.5465/amj.2009.43670894

[28] Atta, M., Khan, M.J. (2016). Perceived organizational politics, organizational citizenship behavior and job attitudes among university teachers. Journal of Behavioural Sciences, 26(2).

[29] De Clercq, D., Belausteguigoitia, I. (2017). Mitigating the negative effect of perceived organizational politics on organizational citizenship behavior: Moderating roles of contextual and personal resources. Journal of Management \& Organization, 23(5): 689-708. https://doi.org/10.1017/jmo.2017.7

[30] Khan, N.A., Khan, A.N., Gul, S. (2019). Relationship between perception of organizational politics and organizational citizenship behavior: testing a moderated mediation model. Asian Business \& Management, 18(2): 122-141. https://doi.org/10.1057/s41291-018-00057-9

[31] Kacmar, K.M., Carlson, D.S. (1997). Further validation of the perceptions of politics scale (POPS): A multiple sample investigation. Journal of management, 23(5): 627-658. https://doi.org/10.1177/014920639702300502

[32] Hair Jr, J.F., Hult, G.T.M., Ringle, C., Sarstedt, M. (2016). A Primer on Partial Least Squares Structural Equation Modeling (PLS-SEM). Sage publications.

[33] Fornell, C., Larcker, D.F. (1981). Evaluating structural equation models with unobservable variables and measurement error. Journal of Marketing Research, $18(1)$ : 39-50. https://doi.org/10.1177/002224378101800104

[34] Hair Jr, J.F., Sarstedt, M., Hopkins, L., Kuppelwieser, V.G. (2014). Partial least squares structural equation modeling (PLS-SEM): An emerging tool in business research. European Business Review, 26(2): 106-121. https://doi.org/10.1108/EBR-10-2013-0128 